\title{
EXTRAÇÃO DO ÓLEO BRUTO DE SEMENTES DE UVA BORDÔ
}

\author{
M. P. SILVA ${ }^{1}$, A. T. SALVADOR ${ }^{1}$, J. G. SGORLON ${ }^{1}$, M. C. S. GOMES ${ }^{1}$ e M. L. \\ MENEZES $^{1}$ \\ ${ }^{1}$ Universidade Tecnológica Federal do Paraná, Departamento de Engenharia Química \\ E-mail para contato: marcoss@alunos.utfpr.edu.br
}

\begin{abstract}
RESUMO - Os insumos agrícolas utilizados na indústria geram uma enorme quantidade de resíduos resultantes do seu processamento. Na indústria vinícola, a semente da uva é um dos subprodutos da elaboração dos vinhos e apresenta um grande potencial no que se refere a sua composição em lipídios. Sendo assim, o objetivo deste trabalho foi determinar a melhor condição de extração do óleo bruto de sementes de uva Bordô, analisando a influência da temperatura de secagem das sementes e o tempo de extração no teor de óleo obtido. Foi utilizada a técnica de extração por Soxhlet usando o etanol como solvente, baseando-se para isso em suas propriedades intrínsecas, como baixa toxicidade, baixo ponto de ebulição, alta polaridade. A otimização do processo foi determinada pela metodologia de superfície de resposta através do delineamento composto central rotacional (DCCR). Os resultados mostraram que o acréscimo da temperatura de secagem das sementes e do tempo de extração favorecem o processo, sendo a melhor condição verificada em sementes previamente secas à $60^{\circ} \mathrm{C}$ e um período de 14 horas de extração. Nessas circunstâncias, os teores de óleo obtidos foram de aproximadamente 18 a $20 \%$.
\end{abstract}

\section{INTRODUÇÃO}

Originária da Ásia, a uva é uma das frutas mais presentes na alimentação humana e são inúmeros os benefícios de seu consumo. No Brasil, segundo a Embrapa, apesar da crise econômica e o baixo desempenho da economia, a produção de uva cresceu 4,41 \% em 2015, comparativamente ao ano de 2014 . No mesmo período, a quantidade de uvas processadas para a elaboração de vinhos e sucos apresentou um aumento de 16,03\%.

A semente da uva é um dos resíduos agroindustriais desse processamento, o qual no decorrer dos anos vem sendo usado principalmente como ração para gado e adubo nas próprias vinícolas. Todavia, as uvas abrigam em suas sementes um grande potencial, apresentando teores de óleos variados, que oscilam de 13 a $20 \%$ (Clemente et al., 2008).

Assim, objetivando-se encontrar soluções viáveis para o aproveitamento desse resíduo, inclusive no desenvolvimento de novos produtos, a produção do óleo da semente de uva se apresenta como uma opção promissora, relacionados principalmente a sua composição peculiar, rica em ácidos graxos essenciais e um elevado potencial antioxidante em virtude do alto teor de vitamina E (Fraga et al., 2013; Fernandes et al., 2013). 
Essa composição depende, entre outros fatores, da variedade e da técnica utilizada. A extração de óleos consiste em três métodos básicos, usados combinados entre si ou separadamente, conforme a natureza da matéria prima e sua composição em lipídios, denominados, respectivamente, de prensa hidráulica por batelada, prensam mecânica contínua e extração por solventes (Pighinelli, 2010).

O método de extração com solventes à quente utilizando o aparelho Soxhlet, segundo Freitas (2007), consiste basicamente em colocá-los em contato com a matriz vegetal em ciclos contínuos, e tem-se demonstrado eficiente para extrações do óleo bruto de sementes de uva conforme apresentado nos estudos de Menezes (2014) e Fernandes et al. (2013), os quais constataram um maior rendimento obtido nas extrações usando o extrator Soxhlet do que em comparação as outras técnicas, como a extração supercrítica com $\mathrm{CO}_{2}$, com e sem o emprego de co-solventes, a maceração ultrassônica e a prensagem.

Todavia, de acordo com Menezes (2014), o emprego de temperaturas elevadas para extração de óleos vegetais por Soxhlet podem ocasionar a formação de ácidos graxos livres, devido à quebra de ligações entre ácidos graxos e o glicerol, prejudicando-se assim a qualidade do material extraído.

Sendo assim, o objetivo do presente trabalho foi determinar a melhor condição de extração do óleo bruto de sementes de uva Bordô, analisando a influência da temperatura de secagem das sementes e o tempo de extração no teor de óleo obtido. Foi utilizado o Soxhlet, uma metodologia clássica, e como solvente o etanol, devido à sua baixa toxicidade, baixo ponto de ebulição, alta polaridade, além de um preço acessível no mercado.

\section{METODOLOGIA}

As operações de secagem e extração do óleo bruto de semente de uva Bordô foram realizadas no Laboratório de Pesquisa M 103 da Universidade Tecnológica Federal do Paraná - Câmpus Apucarana.

\subsection{Materiais}

As sementes de uva da variedade Bordô foram adquiridas na Vinícola Vinhos Randon Ltda, localizada na cidade de Pinheiro Preto/SC. O período de safra foi de meados de dezembro de 2010 até final de março de 2011.

\subsection{Métodos}

As sementes foram limpas e secas à temperatura ambiente, embaladas em sacos plásticos e armazenadas a $-15^{\circ} \mathrm{C}$.

O delineamento experimental do processo de extração utilizado no presente trabalho está exposto na Tabela 1, no qual os fatores analisados são a temperatura de secagem das sementes e o tempo de extração, observando o efeito desses fatores no teor de óleo, a resposta. Conforme salientado por Rodrigues e Iemma (2009), o planejamento experimental constitui de alterações intencionais em parâmetros de entrada pré-determinados, observando e 
identificando as alterações em respostas de saída, caracterizando-se por ser uma série de testes.

Tabela 1 - Planejamento de Experimentos

\begin{tabular}{ccccc}
\hline Ordem & Corrida & Blocos & Tempo $(\mathrm{h})$ & Temperatura $\left({ }^{\circ} \mathrm{C}\right)$ \\
\hline 1 & 4 & Fact & 6,93 & 45,86 \\
2 & 8 & Fact & 21,07 & 45,86 \\
3 & 10 & Fact & 6,93 & 74,14 \\
4 & 5 & Fact & 21,07 & 74,14 \\
5 & 1 & Axial & 4 & 60 \\
6 & 12 & Axial & 24 & 60 \\
7 & 9 & Axial & 14 & 40 \\
8 & 11 & Axial & 14 & 80 \\
9 & 3 & Center & 14 & 60 \\
10 & 13 & Center & 14 & 60 \\
11 & 6 & Center & 14 & 60 \\
12 & 2 & Center & 14 & 60 \\
13 & 7 & Center & 14 & 60 \\
\hline
\end{tabular}

Sendo assim, as sementes de uva Bordô foram previamente secas nas temperaturas de 40, 46, 60, 74 e $80^{\circ} \mathrm{C}$, em estufa Solab-102. Além disso, antes de cada extração, as sementes foram trituradas em um liquidificador (modo Pulsar) por 10 segundos, homogeneizadas e trituradas por mais 10 segundos.

Para as extrações foi utilizado como solvente o etanol $\left(\mathrm{PE}: 80^{\circ} \mathrm{C}\right)$, sendo as extrações realizadas na temperatura de ebulição do solvente. As extrações do óleo em cada corrida experimental, apresentadas na Tabela 1, foram realizadas em triplicata com, aproximadamente, $10 \mathrm{~g}$ de sementes previamente limpas, secas e trituradas e $300 \mathrm{~mL}$ de solvente.

Após o período de extração, a amostra contendo o óleo e o solvente (extrato) ficou recolhida no balão. A seguir, o extrato foi levado a um evaporador rotativo para a recuperação do solvente. Então, foi realizado o cálculo do teor de óleo extraído, conforme mostra a Equação 1.

$\%$ Teor de óleo $=\left(\mathrm{m}_{\text {óleo }} / \mathrm{m}_{\text {semente }}\right) \times 100$

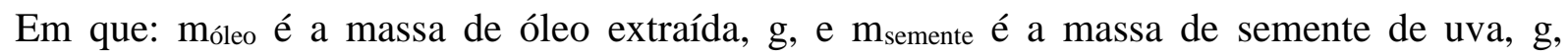
utilizada em cada extração.

\section{RESULTADOS E DISCUSSÕES}

Para a extração por Soxhlet utilizando o etanol como solvente, o modelo ajustado avaliando-se a influência da temperatura de secagem das sementes e do tempo de extração para as sementes de uva Bordô está indicado pela Equação 2. 
Teor $=-29,5766+1,8825 \cdot X_{t}+0,9487 \cdot X_{T}-0,0572 \cdot X_{t}{ }^{2}-0,0077 \cdot X_{T}{ }^{2}+0,0032 \cdot X_{t} X_{T}(2)$

Estão apresentados na Tabela 2 os resultados da análise de variância para a extração por Soxhlet, usando sementes de uva Bordô e álcool etílico como solvente.

Tabela 2 - Análise de variância para a extração

\begin{tabular}{c|c|c|c|c|c}
\hline Fonte de Variação & $\begin{array}{c}\text { Soma dos } \\
\text { Quadrados }\end{array}$ & $\begin{array}{c}\text { Graus de } \\
\text { Liberdade }\end{array}$ & $\begin{array}{c}\text { Soma dos } \\
\text { Quadrados } \\
\text { Médios }\end{array}$ & F & p-valor \\
\hline Tempo & 77,2367 & 1 & 77,2367 & 10,88582 & 0,002330 \\
\hline Tempo $^{2}$ & 170,7703 & 1 & 170,7703 & 24,06854 & 0,000024 \\
\hline Temperatura $_{\text {Temperatura }}^{2}$ & 47,1360 & 1 & 47,1360 & 6,64340 & 0,014608 \\
\hline Temperatura*Tempo & 49,7352 & 1 & 49,7352 & 7,00973 & 0,012334 \\
\hline Erro Total & 49,7352 & 1 & 1,2208 & 0,17206 & 0,680968 \\
\hline
\end{tabular}

Por meio do valor apresentado pelo parâmetro p-valor, exposto na Tabela 2, pode-se notar que a temperatura de secagem das sementes e o tempo de extração foram significativos no processo. As interações Temperatura ${ }^{2}$ e Tempo ${ }^{2}$ também se demonstraram de tal forma, uma vez que a ANOVA indicou p-valor inferior a 0,05 para ambas variáveis e interações.

Freitas (2007) relatou que em técnicas convencionais, como o Soxhlet, o aumento da temperatura do processo de extração, ocasiona um suposto aumento no rendimento. Acréscimo esse causado pelo aumento da capacidade do solvente solubilizar a amostra, devido ao enfraquecimento das ligações de hidrogênio entre o analito e a matriz, ocorrendo, portanto, um decréscimo da viscosidade e da tensão superficial do solvente, facilitando a sua entrada nos poros da matriz (semente de uva).

A Figura 1 mostra a superfície de resposta obtida usando o software Statistica 13.0, para a extração por Soxhlet utilizando sementes de uva Bordô e o etanol como solvente. 
Figura 1 - Superfície de resposta obtida para a extração do óleo de semente de uva Bordô

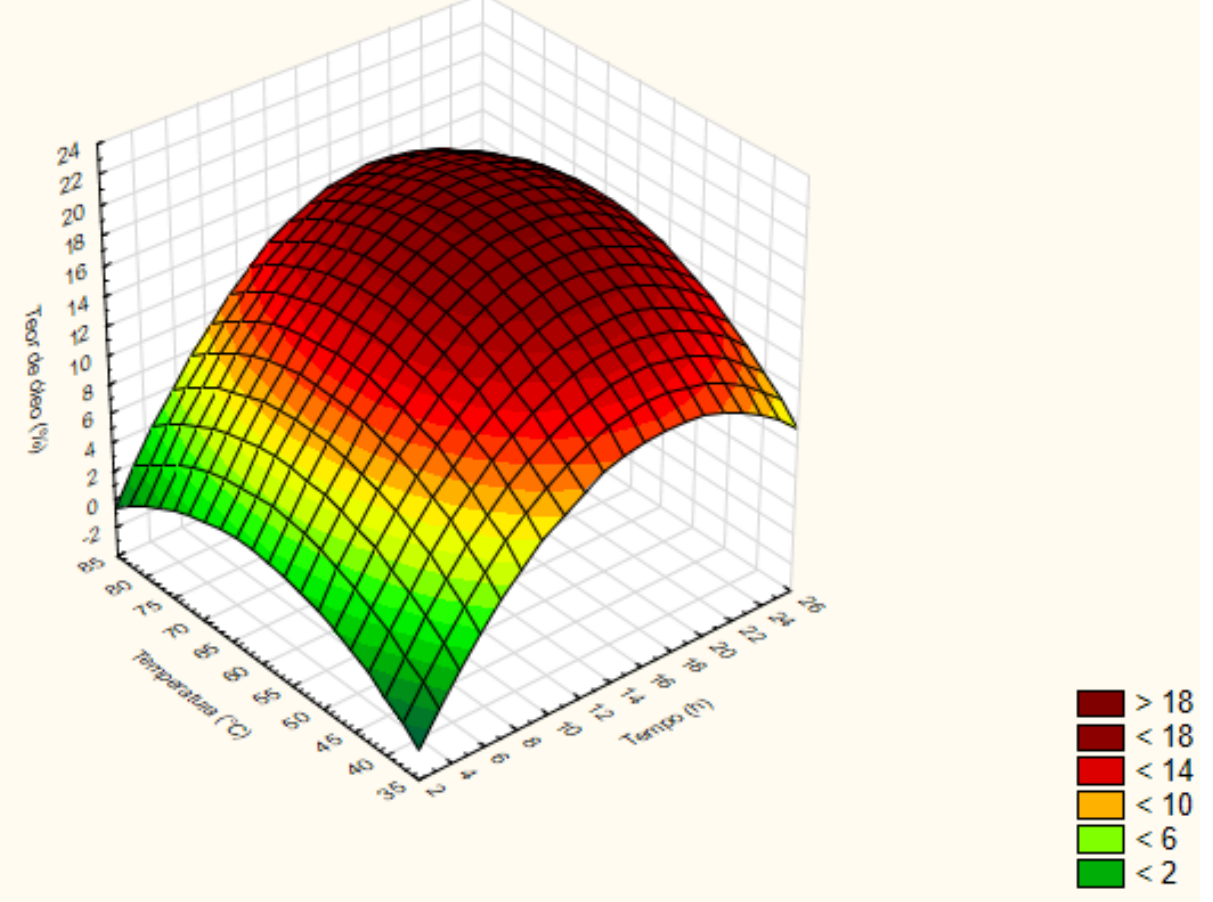

Analisando a Figura 1 é possível verificar que a melhor condição de extração por Soxhlet do óleo de sementes de uva Bordô, com base no maior teor de óleo, foi obtida utilizando sementes secas em elevadas temperaturas $\left(60\right.$ e $\left.80^{\circ} \mathrm{C}\right)$, sendo a primeira preferível por demandar menos gasto energético. O teor de óleo obtido no tempo de extração de 24 horas não diferiu significativamente do obtido em 14 horas de extração, sendo este último, portanto, o melhor tempo de extração. Na melhor condição de extração, os teores de óleo obtidos foram de aproximadamente 18 a $20 \%$.

Os teores de óleos teoricamente altos encontrados no presente trabalho podem ser decorrentes do poder de orientação dos dipolos que o etanol possui. Uma vez que o valor de sua constante dielétrica é de aproximadamente $24,5 \varepsilon$, o que faz com que este solvente extraia tanto compostos polares quanto apolares, sendo capaz de solvatar bem os íons mantendo-os dissociados em solução. Outro fator que explica o resultado obtido, é que o solvente utilizado no processo de extração possui estrutura pequena e essa característica faz com que haja uma maior facilidade na entrada do solvente nos poros das sementes, extraindo-se assim consequentemente um maior teor de óleo (Lowery e Richardson, 1987).

Os teores de óleos verificados nessa pesquisa foram próximos aos obtidos por Menezes (2014) utilizando-se diclorometano como solvente na extração do óleo de sementes de uva Carbenet Sauvignon e Bordô, respectivamente, 20 e 16,5\%.

No trabalho de Freitas (2007), foram obtidos os seguintes teores $(\mathrm{m} / \mathrm{m})$ de óleo com o Soxhlet, sendo o hexano o solvente utilizado e um tempo de extração de 20 horas: $7,4 \%$ para as sementes de Isabel, 10,8\% para as sementes de Moscatel, 11,1\% para sementes de Seibel/Isabel e Cabernet Sauvignon, 12,7\% para sementes de Herbemont/Isabel e 13,4\% para sementes de uva Merlot. Analisando todas condições descritas anteriormente, constata-se que 
os teores de óleo verificados no presente trabalho, no processo de otimização, entre 18 a 20 $\%$, foram superiores quando contrastados aos apresentados pela pesquisadora.

\section{CONCLUSÕES}

A metodologia utilizada para a extração do óleo de semente de uva Bordô foi eficiente e apresentou bons resultados com relação ao teor de óleo extraído, estando em concordância com os valores encontrados na literatura, que estão entre 10 e $20 \%$, dependendo da variedade da uva. Verificou-se ainda que maiores temperaturas de secagem das sementes e um maior período de extração favoreceram o processo, sendo a otimização da extração por Soxlhet utilizando etanol como solvente verificada em sementes previamente secas à $60^{\circ} \mathrm{C}$ e um tempo de 14 horas de extração. Nessa melhor condição de extração, os teores de óleo obtidos foram de aproximadamente 18 a $20 \%$.

\section{REFERENCIAS}

CLEMENTE, G.; BON, J.; BENEDITO, J.; SANJUÁN, N.; MULET, A. Temperature influence on grape seeds dehydration. 16th International Drying Symposium, Hyderabad, Índia, 2008.

EMBRAPA, Desempenho da vitivinicultura brasileira em 2015. Disponível em: $<$ https://www.embrapa.br/busca-de-noticias/-/noticia/9952204/artigo-desempenho-davitivinicultura-brasileira-em-2015>. Acesso em 20 out 2016.

FERNANDES, L.; CASAL, S; CRUZ, R.; PEREIRA, J.A.; RAMALHOS, E. Seed oils of tem traditional Portuguese grape varieties with interesting chemical and antioxidante properties. Food Res. Inter., v. 50, p. 66-161, 2013.

FRAGA, H. et al. Future scenarios for viticultural zoning in Europe: ensemble projections and uncertainties. Inter. Journal of Biomet., v. 57, n. 6, p. 909-925, 2013.

FREITAS, L. S., Desenvolvimento de procedimentos de extração do óleo de semente de uva e caracterização química dos compostos extraídos. 2007. Tese (Doutorado em Química), Universidade Federal do Rio Grande do Sul, Porto Alegre, 2007.

LOWERY, T. H.; RICHARDSON, K.S.; Mechanism and Theory in Organic Chemistry, Harper Collins Publishers, Ed. 3, p.181-183, 1987.

MENEZES, M. L. Estudo dos processos de secagem e de extração da produção do óleo bruto de semente de uva. 2014. 288 f. Tese (Doutorado em Engenharia Química) Universidade Estadual de Maringá, Maringá, 2014.

PIGHINELLI, A. L. M. T. Estudo da extração mecânica e da transesterificação etílica de óleos vegetais. 2010. Tese (Doutorado em Engenharia Agrícola), Universidade Estadual de Campinas, Campinas, 2010.

RODRIGUES, M. I.; IEMMA, A. F. Planejamento de Experimentos e Otimização de Processos. Cárita Editora, 2 ed., 358p., Campinas, 2009. 